\title{
A program for automated data mining of PubChem to screen a billion compounds and generate by machine learning based AutoQSAR algorithm anti-corona viral drug leads (replicase polyprotein 1ab inhibitors) and In Silico study of the top drug lead compounds
}

\author{
Ben Geoffrey A S*a,c , Akhil Sanker ${ }^{\mathrm{b}}$, Host Antony David ${ }^{\mathrm{a}}$ Judith Gracia $^{\mathrm{c}}$ \\ a, Madras Christian College, East Tambaram, Chennai 600 059, India \\ b SRM Institute of Science and Technology, Ramapuram, Chennai 600 089, India \\ c University of Madras, Chepauk, Chennai 600 005, India
}

*Corresponding author email : bengeof@gmail.com

\begin{abstract}
Our work is composed of a python program for automatic data mining of PubChem database to collect data associated with the corona virus drug target replicase polyprotein 1ab (UniProt identifier : POC6X7 ) of data set involving active compounds, their activity value (IC50) and their chemical/molecular descriptors to run a machine learning based AutoQSAR algorithm on the data set to generate anti-corona viral drug leads. The machine learning based AutoQSAR algorithm involves feature selection, QSAR modelling, validation and prediction. The drug leads generated each time the program is run is reflective of the constantly growing PubChem database is an important dynamic feature of the program which facilitates fast and dynamic anti-corona viral drug lead generation reflective of the constantly growing PubChem database. The program prints out the top anti-corona viral drug leads after screening PubChem library which is over a billion compounds. The interaction of top drug lead compounds generated by the program and two corona viral drug target proteins, 3-Cystiene like Protease (3CLPro) and Papain like protease (PLpro) was studied and analysed using molecular docking tools. The compounds generated as drug leads by the program showed favourable interaction with the drug target proteins and thus we recommend the program for use in anti-corona viral compound drug lead generation as it helps reduce the complexity of virtual screening and ushers in an age of automatic ease in drug lead generation. The leads generated by the program can further be tested for drug potential through further In Silico, In Vitro and In Vivo testing
\end{abstract}




\section{Introduction}

PubChem database is a publically accessible bio and chemical data repository of over a billion compounds and their bioactivity data [1]. The programmatic access to PubChem database can be accomplished through web API packages such as PUB-REST and PyPubChem by which data mining for a particular task can be automated by programmatic access to the database using python commands $[2,3]$. Statistically predicted drug leads can be generated from a QSAR model for a particular pharmacological activity [4-7]. However the data sets used in QSAR modelling has to be curated each time by researchers' before carrying out the study. In our present efforts, we have automated the process of data set fetching required for a QSAR study which is associated with a particular drug target by programmatic access to PubChem database through python commands. Therefore, each time, the drug leads generated each time are reflective of the constantly growing PubChem database. The drug targets for corona virus were identified from literature [8] and this work automates the process of drug lead generation for the corona virus drug target, replicase polyprotein 1ab (UniProt identifier: POC6X7) and generates drug leads each time reflective of the PubChem database which constantly growing at each time. Replicase polyprotein $1 \mathrm{ab}$ inhibitors are compounds that are found active against the replication of the virus by inhibiting the replicase enzyme encoded by the virus, replicase polyprotein $1 \mathrm{ab}$ (UniProt identifier: POC6X7 ). The drug leads generated by this software can further be carried forward to In Silico, In Vitro and In Vivo testing

\section{Methods and Techniques}

The workflow of the algorithm implemented as code is shown in Fig.1. The first process involved is data mining the PubChem database for the compounds that possess activity against the drug target of corona virus and collecting the data set involving the molecular descriptors and IC50 values corresponding to a particular drug target of the compound. This is accomplished through programmatic access to PubChem database through python commands $[11,12]$. The second process involves implementing a machine learning based AutoQSAR. The workflow of a machine learning based AutoQSAR involves feature learning and descriptor selection, QSAR modelling, validation and prediction [13-15]. The last process as given in the workflow chart involves a programmatic querying of PubChem database to generate new drug leads from compounds in PubChem database that are structurally associative to compounds in QSAR dataset but have been tested experimentally. 
Running the program requires no more programming knowledge than running the python executable file in python 3 environment along with some python dependency packages installed such as :

pandas $==1.0 .1$

numpy

matplotlib

scikit-learn

seaborn

The program is hosted, maintained and supported at the GitHub repository https://github.com/bengeof/Drug-Discovery-P0C6X7

The run time of the program is expected to be a few hours with variation based on CPU and internet speed. As final output the program prints out the top 30 drug leads which are identified with PubChem CIDs that are printed out and the final output is shown in Fig.2 and the names associated with each CID is provided in Table 1.

The structure of top lead drug compounds generated by the program was retrieved from PubChem database (http://pubchem.ncbi.nlm.nih.gov/) and three-dimensional structure was developed using ChemDraw Ultra V12.0 [16]. The crystal structure of two corona viral protein drug targets was downloaded from the RCSB-PDB database [17] with PDB IDs : 1P9U, 6X9C. The drug - target protein interaction was studied using AutoDock Tools. Computational docking analysis was evaluated using Auto Dock tools [18] (ADT version 1.5.4 and 4.2 programs). Parameters like atomic solvation and Kollman charges were added. Nonpolar hydrogen's were merged with the carbons and the polar hydrogen charges of the Gasteiger type were assigned with the carbons with the internal degrees of freedom and torsions were set. The lead compounds identified with PubChem CIDs : 49856716, 127045221, 5470475, 4582403, 91808054, 127045386, 127045229, 127045220, 143349197, 127043642 was docked with the corona viral drug targets 3CLPro and PLpro. The molecule was considered as a rigid body and the ligand being flexible, the search was extended over the active sites of the receptor protein.

Similarity maps and electrostatic maps for all the presented atom types were computed with a grid spacing of $0.375 \AA$. Lamarckian genetic algorithm (LGA) [19] was carried out using 
prolonged docking search at the maximum of 2,500,00 energy evaluations and populations of 150 individuals with a mutation rate of 0.02 were evolved for 10 generations. The result was calculated by organizing out the different pose complexes with respect to the projected binding energy value. Hydrogen binding and hydrophobic interactions between docked effective agents were analyzed using PyMOL viewer [20, 21].

\section{Results and Discussion}

The python executable file was run in Python 3 environment with the dependency packages mentioned above. The run time of the program is about a few hours however it is expected to vary depending on CPU and internet speed on different machines. The output screen of the program is shown in Fig.2. The program prints out the PubChem CID of compounds that are the best 30 possible anti-corona viral drug leads that are expected to be potent replicase polyprotein $1 \mathrm{ab}$ inhibitors. It does so by an automated programmatic data mining of PubChem database and by implementing a machine learning based AutoQSAR algorithm on the dataset. From the PubChem compound identifiers ID these compounds were identified with names and are presented in Table 1 . The drug leads generated by the program for the corona viral drug target - replicase polyprotein 1ab are useful to screen PubChem database which is over a billion compounds, and the leads are useful to further pursue In Silico, In Vitro and In Vivo testing and is expected to save computational and experimental testing costs for the pharmaceutical industry.

The interaction of the top drug lead compounds generated by the program and two corona viral drug target proteins 3CLPro and PLpro were studied using AutoDock tools. The interaction of 3CLPro and the top drug lead compounds generated by the program identified with PubChem CIDs is shown in Fig. 3a, 3b \& 3c. The interacting residues, bond lengths and lowest binding energy are tabulated in Table 2 . The drug lead compounds generated by the program showed favourable interaction with the corona viral drug target protein 3CLPro. The compounds associated with PubChem CIDs : 49856716, 127045221, 4582403, 127045386, $127045229,127045220,143349197,127043642$ possessed a binding energy of less than $10.00 \mathrm{kcal} / \mathrm{mol}$ and the compound 3-[(4Z)-5-Oxo-3-phenyl-4-[(4phenylmethoxyphenyl)methylidene]pyrazol-1-yl]benzoic acid with PubChem CID: 127045386 was found possessing a binding energy of $-13.36 \mathrm{Kcal} / \mathrm{mol}$ with the corona viral target protein 3CLPro. 
The interaction of PLpro and the top drug lead compounds generated by the program identified with PubChem CIDs is shown in Fig. 4a, 4b \& 4c. The interacting residues, bond lengths and lowest binding energy are tabulated in Table 3. The drug lead compounds generated by the program showed favourable interaction with the corona viral drug target protein PLPro. The compounds associated with PubChem CIDs : 49856716, 127045221, 5470475, 4582403, 127045386, 127045229, 127045220, 143349197, 127043642 possessed a binding energy of less than $-9.00 \mathrm{kcal} / \mathrm{mol}$ and the compound 3-[(4Z)-3-Methyl-5-oxo-4[[4-(1-phenyl-2,3,6,7-tetrahydroazepin-4-yl)phenyl]methylidene]pyrazol-1-yl]benzoic acid with PubChem CID: 143349197 was found possessing a binding energy of $-11.92 \mathrm{Kcal} / \mathrm{mol}$ with the corona viral target protein PLPro.

It was found from the results that the compounds generated as anti-corona viral leads by the program showed favourable interaction with corona viral drug target proteins. Therefore the program helped reduce the complexity of virtual screening for anti-corona viral agents of the PubChem ligand library which is over a billion compounds and therefore the leads generated by the program can further be tested for drug potential through in In Vitro and In Vivo testing.

\section{Conclusion and future scope}

The present work has implemented automatic data mining of PubChem database to collect data associated with corona virus drug targets required to perform autoQSAR modelling and generate drug leads each time the program is run in a way which is reflective of the constantly growing PubChem database. The interaction of top drug lead compounds generated by the program and two corona viral drug target proteins, 3-Cystiene like Protease (3CLPro) and Papain like protease (PLpro) was studied and analysed using molecular docking tools. The compounds generated as drug leads by the program showed favourable interaction with the drug target proteins and thus we recommend the program for use in anticorona viral compound drug lead generation as it helps reduces the complexity of virtual screening PubChem ligand library which is over a billion compounds and leads generated by the program can further be pursued to find possible drug potential through further In Silico, In Vitro and In Vivo testing

The future scope lies in researchers coupling the leads generated by this program as programmatic inputs to In Silico testing packages for a more wholesome and automated drug discovery suite. 


\section{References}

1. Kim, S., Thiessen, P. A., Bolton, E. E., Chen, J., Fu, G., Gindulyte, A., Bryant, S. H. (2015). PubChem Substance and Compound databases. Nucleic Acids Research, 44(D1). doi:10.1093/nar/gkv951

2. Kim, S., Thiessen, P. A., Bolton, E. E., \& Bryant, S. H. (2015). PUG-SOAP and PUG-REST: Web services for programmatic access to chemical information in PubChem. Nucleic Acids Research, 43(W1). doi:10.1093/nar/gkv396

3. Swain, M. (2014). PubChemPy: A way to interact with PubChem in Python.

4. Bhardwaj, V. (2014). Quantitative structure-activity relationship (QSAR) studies as strategic approach in drug discovery. Medicinal Chemistry Research, 23(12), 49915007. doi:10.1007/s00044-014-1072-3

5. Eriksson, L., \& Johansson, E. (1996). Multivariate design and modeling in QSAR. Chemometrics and Intelligent Laboratory Systems, 34(1), 1-19. doi:10.1016/01697439(96)00023-8.

6. Bajot, F. (2009). The Use of Qsar and Computational Methods in Drug Design. Challenges and Advances in Computational Chemistry and Physics Recent Advances in QSAR Studies, 261-282. doi:10.1007/978-1-4020-9783-6_9

7. Sippl, W. (2009). 3D-QSAR - Applications, Recent Advances, and Limitations. Challenges and Advances in Computational Chemistry and Physics Recent Advances in QSAR Studies, 103-125. doi:10.1007/978-1-4020-9783-6_4.

8. Kumar, V., Jung, Y., \& Liang, P. (2013). Anti-SARS coronavirus agents: A patent review (2008 - present). Expert Opinion on Therapeutic Patents, 23(10), 1337-1348. doi:10.1517/13543776.2013.823159.

9. Ziebuhr, J. (2005). The Coronavirus Replicase. Current Topics in Microbiology and Immunology Coronavirus Replication and Reverse Genetics, 57-94. doi:10.1007/3540-26765-4_3

10. Zhang, X. W., \& Yap, Y. L. (2004). Old drugs as lead compounds for a new disease? Binding analysis of SARS coronavirus main proteinase with HIV, psychotic and parasite drugs. Bioorganic \& Medicinal Chemistry, 12(10), 2517-2521. doi:10.1016/j.bmc.2004.03.035

11. Mitchell, R. (2018). Web Scraping with Python: Collecting More Data from the Modern Web. O'Reilly Media, Incorporated. 
12. Vanden Broucke, S., \& Baesens, B. (2018). Practical Web scraping for data science (pp. 3-5). New York, NY: Apress.

13. Dixon, S. L., Duan, J., Smith, E., Von Bargen, C. D., Sherman, W., \& Repasky, M. P. (2016). AutoQSAR: an automated machine learning tool for best-practice quantitative structure-activity relationship modeling. Future medicinal chemistry, 8(15), 18251839.

14. Kim, S., \& Cho, K. H. (2019). PyQSAR: A Fast QSAR Modeling Platform Using Machine Learning and Jupyter Notebook. Bulletin of the Korean Chemical Society, 40(1), 39-44.

15. Rodgers, S. L., Davis, A. M., Tomkinson, N. P., \& van de Waterbeemd, H. (2011). Predictivity of simulated ADME AutoQSAR models over time. Molecular informatics, 30(2-3), 256-266.

16. Cousins, K. R. (2011). Computer review of chemdraw ultra 12.0.

17. Deshpande, N., Addess, K. J., Bluhm, W. F., Merino-Ott, J. C., Townsend-Merino, W., Zhang, Q., ... \& Kramer Green, R. (2005). The RCSB Protein Data Bank: a redesigned query system and relational database based on the mmCIF schema. Nucleic acids research, 33(suppl_1), D233-D237.

18. Forli, S., Huey, R., Pique, M. E., Sanner, M. F., Goodsell, D. S., \& Olson, A. J. (2016). Computational protein-ligand docking and virtual drug screening with the AutoDock suite. Nature protocols, 11(5), 905.

19. Morris, G. M., Goodsell, D. S., Halliday, R. S., Huey, R., Hart, W. E., Belew, R. K., \& Olson, A. J. (1998). Automated docking using a Lamarckian genetic algorithm and an empirical binding free energy function. Journal of computational chemistry, 19(14), 1639-1662.

20. Seeliger, D., \& de Groot, B. L. (2010). Ligand docking and binding site analysis with PyMOL and Autodock/Vina. Journal of computer-aided molecular design, 24(5), 417422.

21. Wang, Q., He, J., Wu, D., Wang, J., Yan, J., \& Li, H. (2015). Interaction of $\alpha-$ cyperone with human serum albumin: Determination of the binding site by using Discovery Studio and via spectroscopic methods. Journal of Luminescence, 164, 8185. 
The authors affirm that we have no conflict of interest to disclose and that the work is original and are not being considered for publication elsewhere 


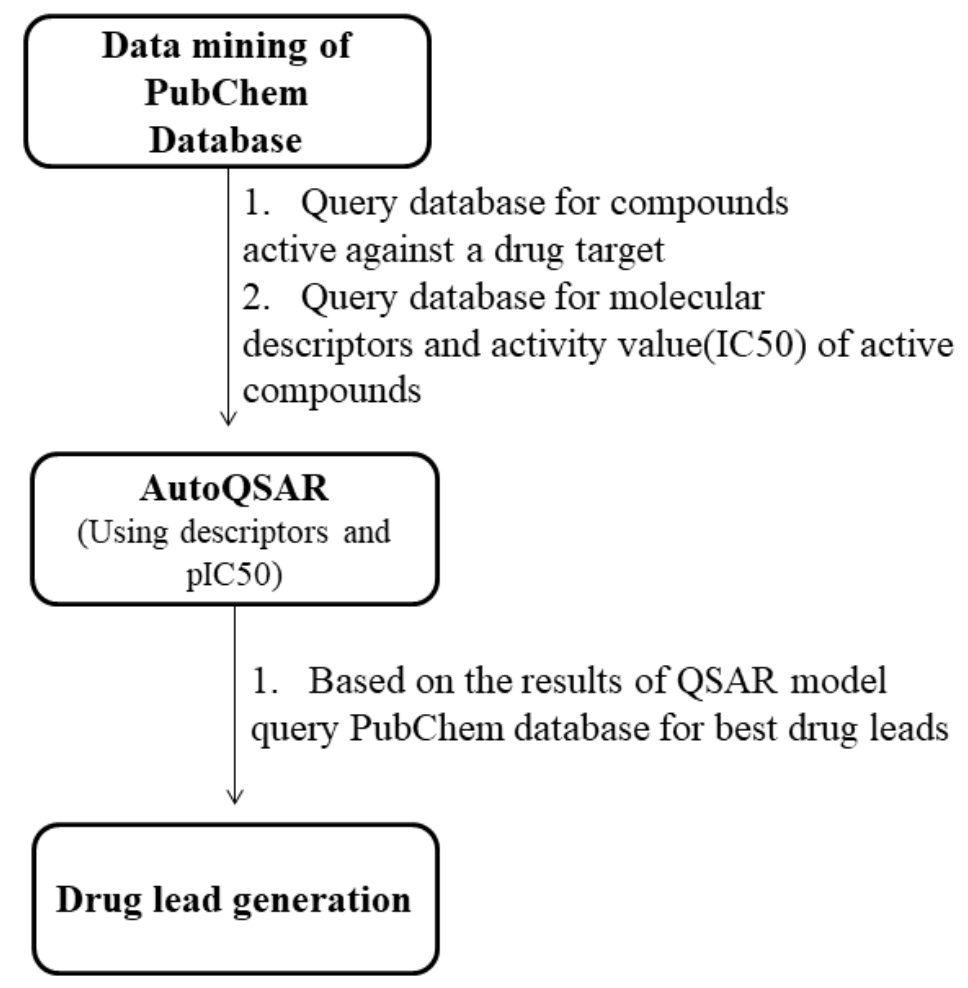

Fig.1 -Workflow flow chart of the program 
Administrator: C: $\backslash$ Windows $\backslash$ System32\cmd.exe

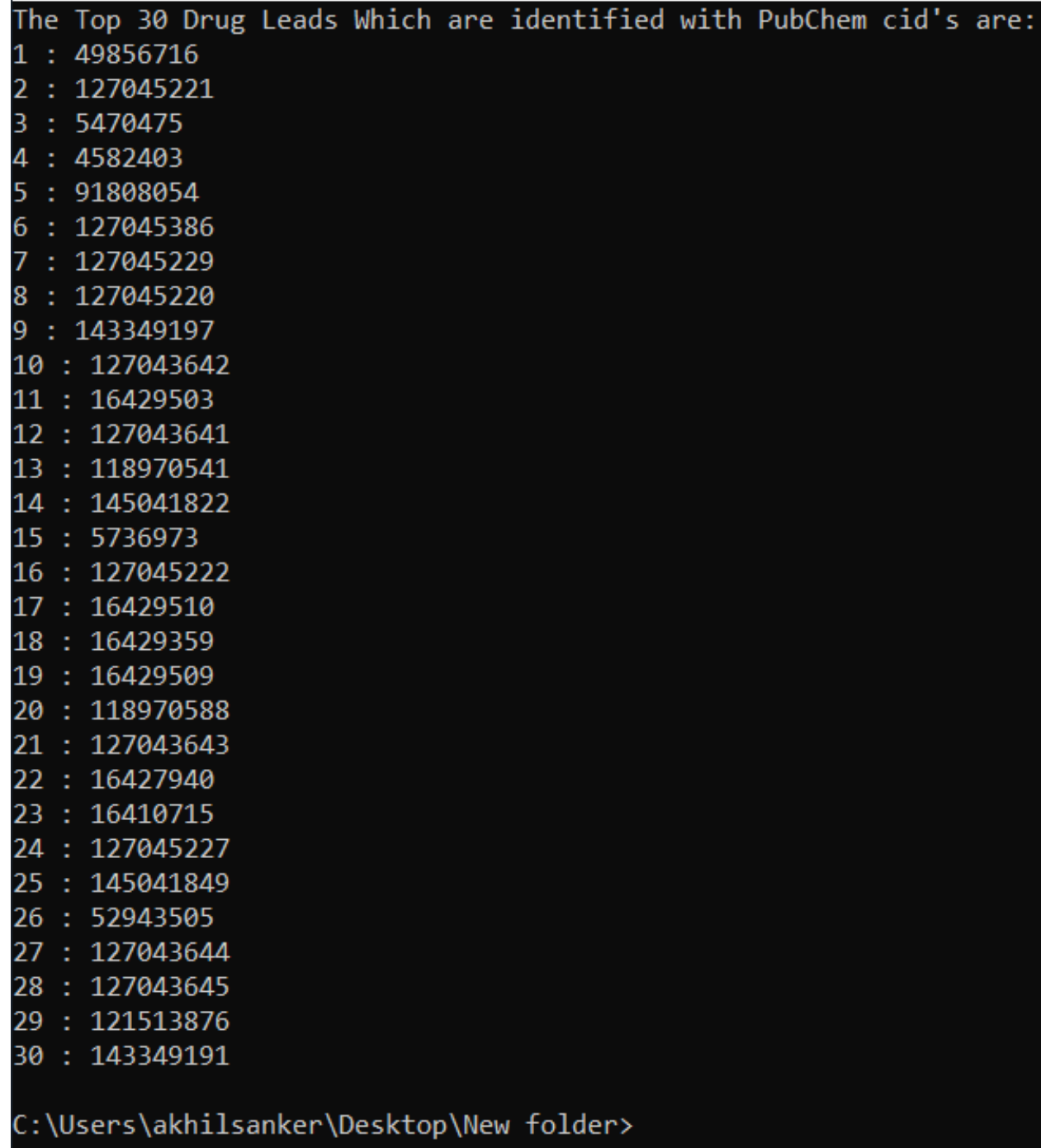

Fig. 2 - Final Output of the drug lead generation program 


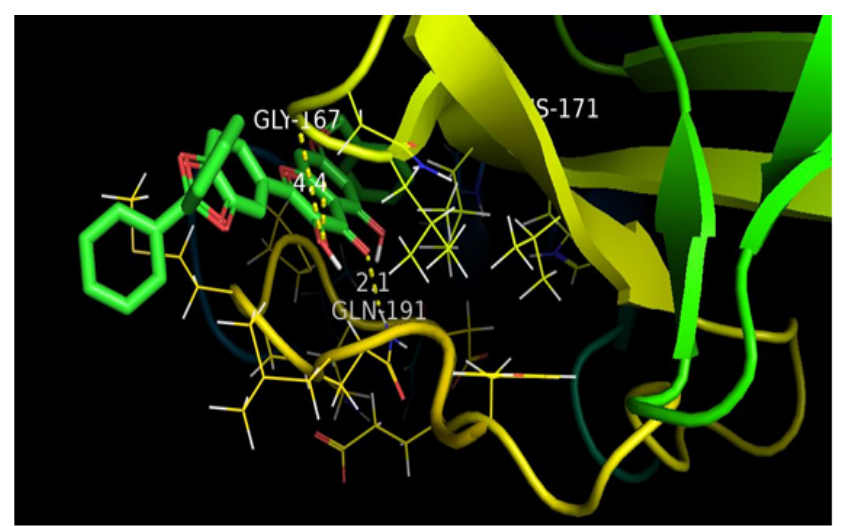

Protein-ligand(CID 716) interaction

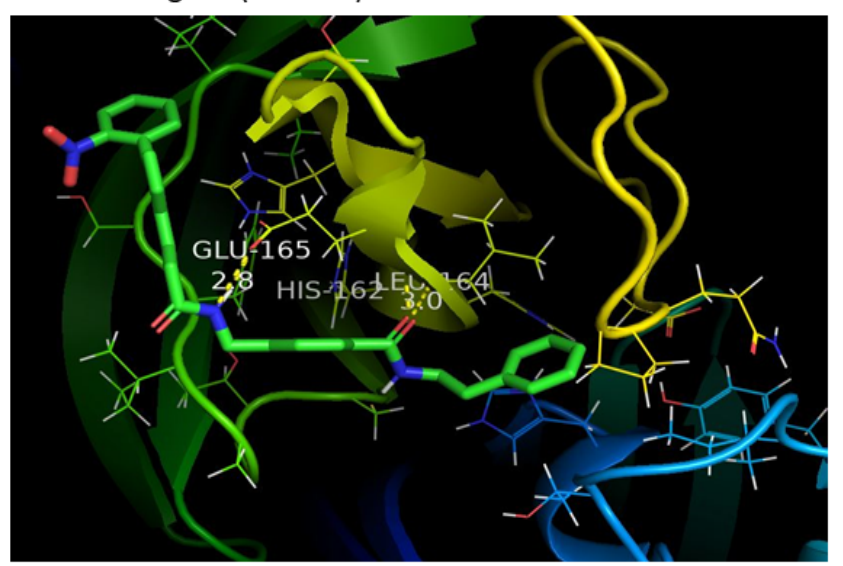

Protein-ligand(CID 475) interaction

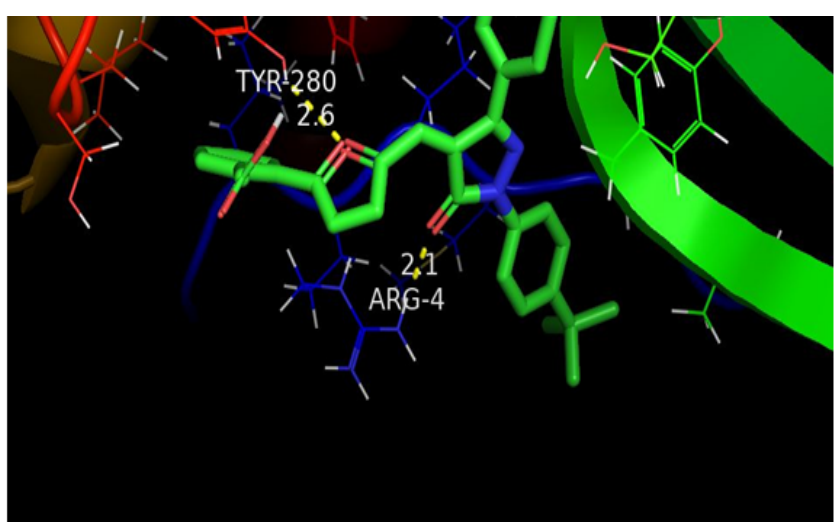

Protein-ligand(CID 221) interaction

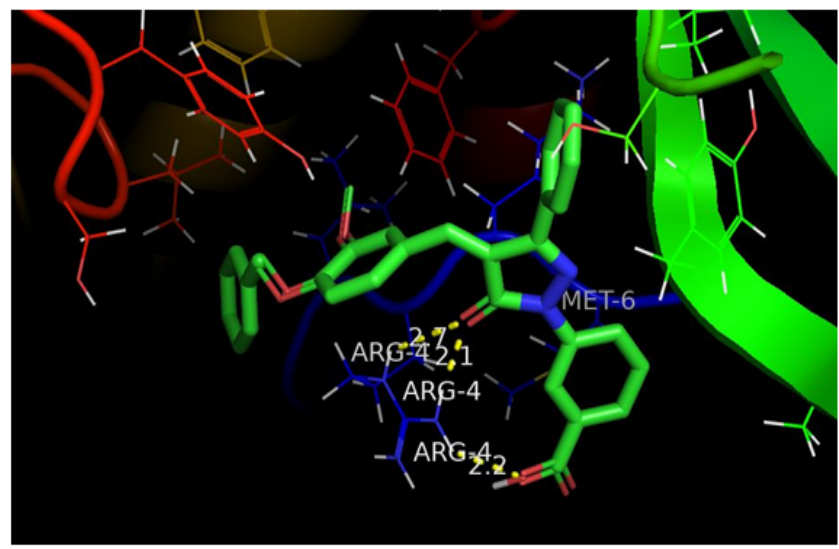

Protein-ligand(CID 403) interaction

Fig. 3a - Interaction of 3CLPro and drug lead compounds generated by the program 


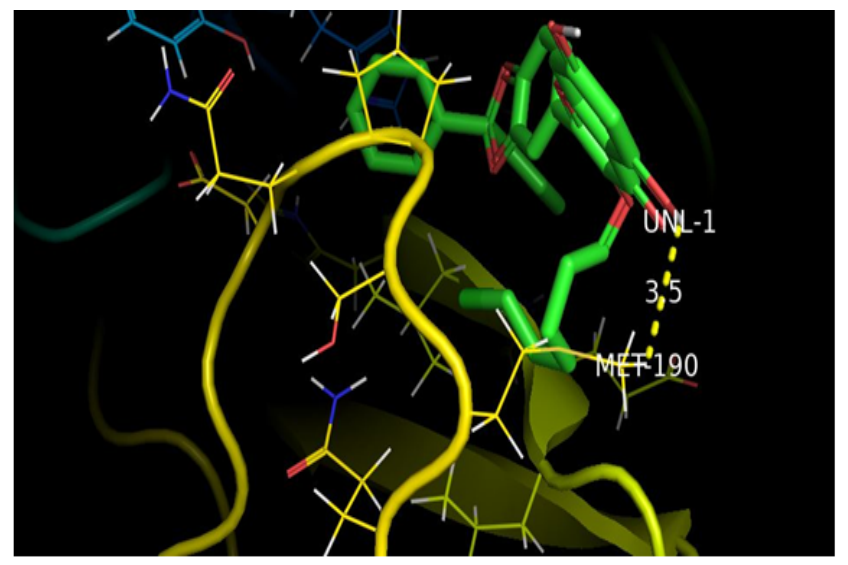

Protein-ligand(CID 054) interaction

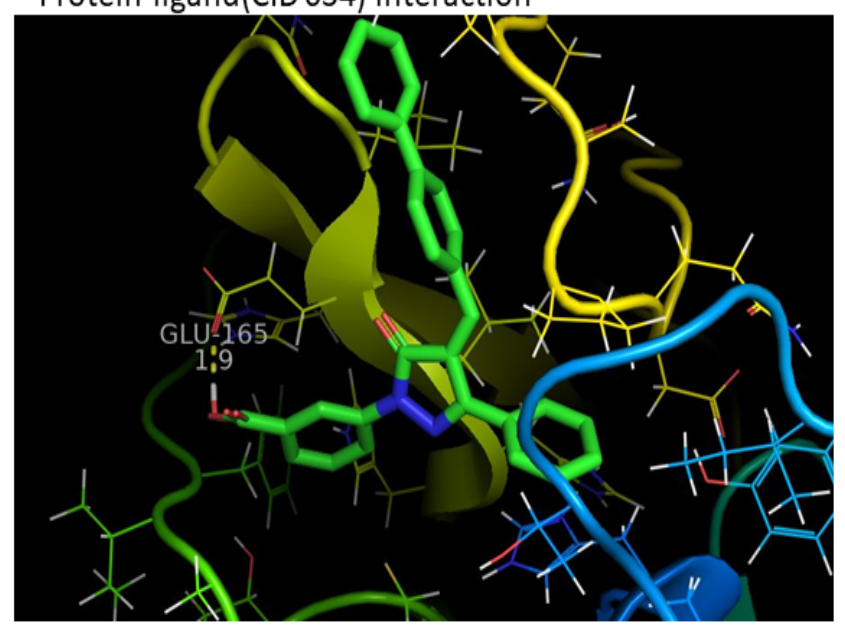

Protein-ligand(CID 229) interaction

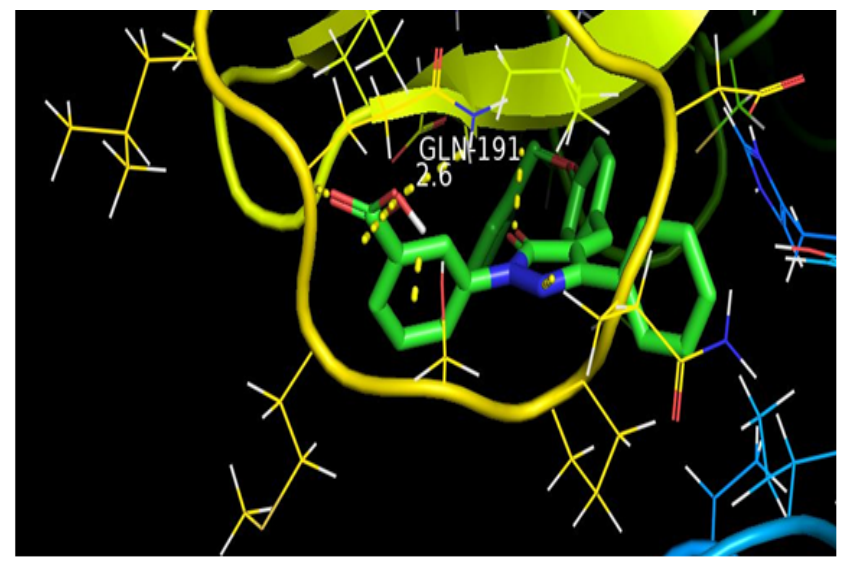

Protein-ligand(CID 386) interaction

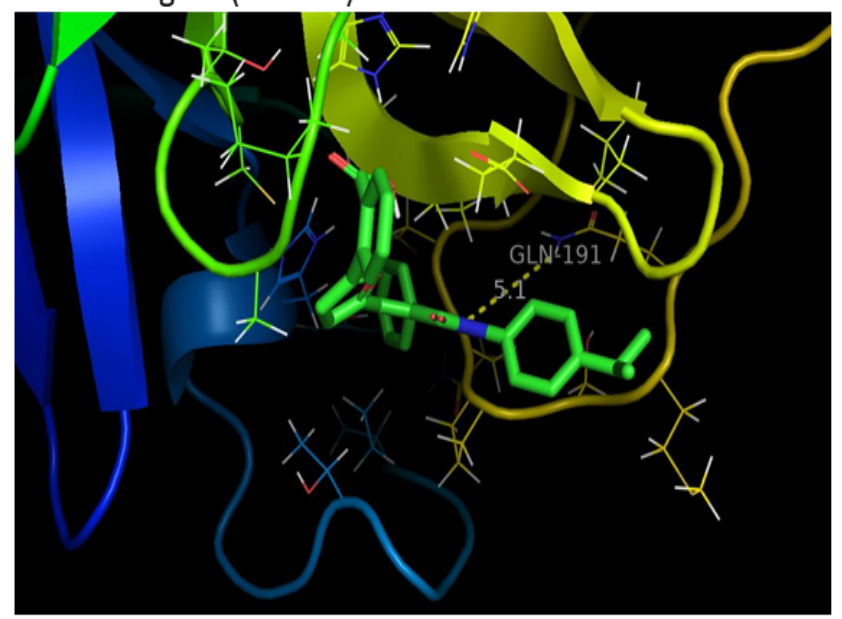

Protein-ligand(CID 220) interaction

Fig. 3b - Interaction of 3CLPro and drug lead compounds generated by the program

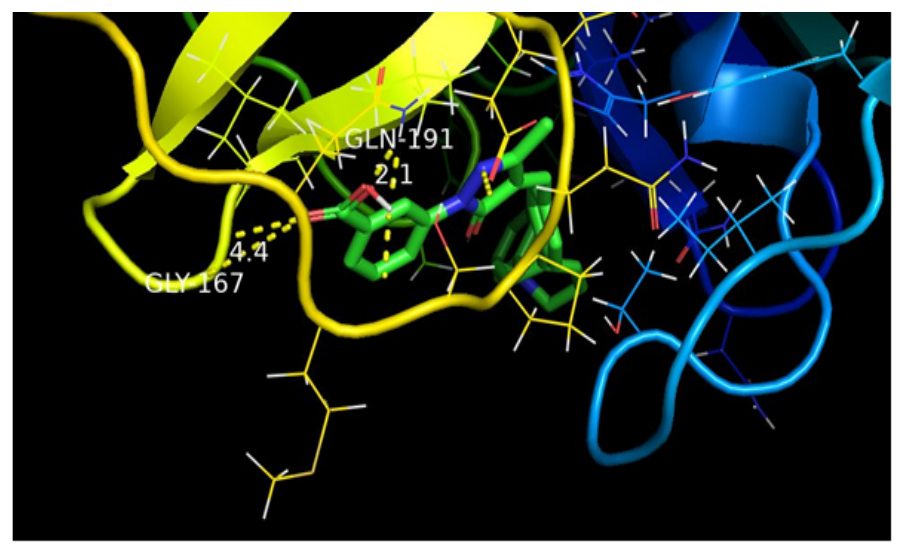

Protein-ligand(CID 197) interaction

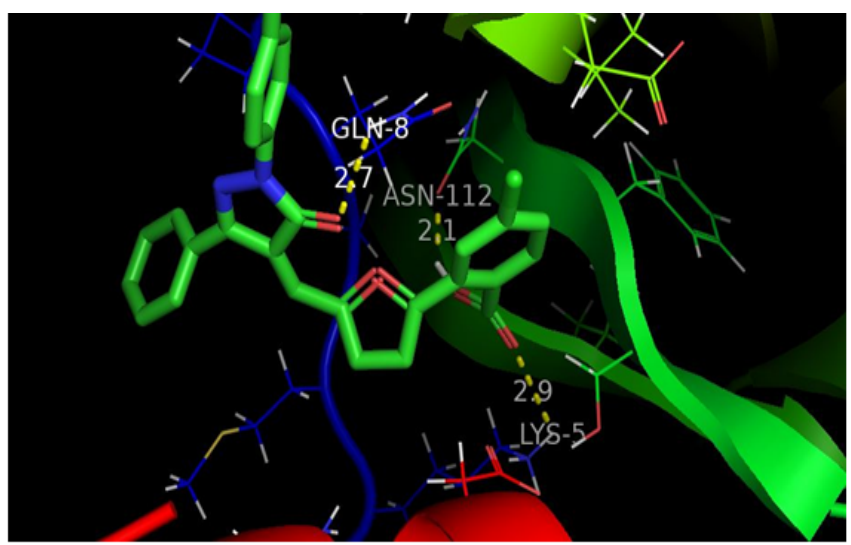

Protein-ligand(CID 642) interaction

Fig. 3c - Interaction of 3CLPro and drug lead compounds generated by the program 


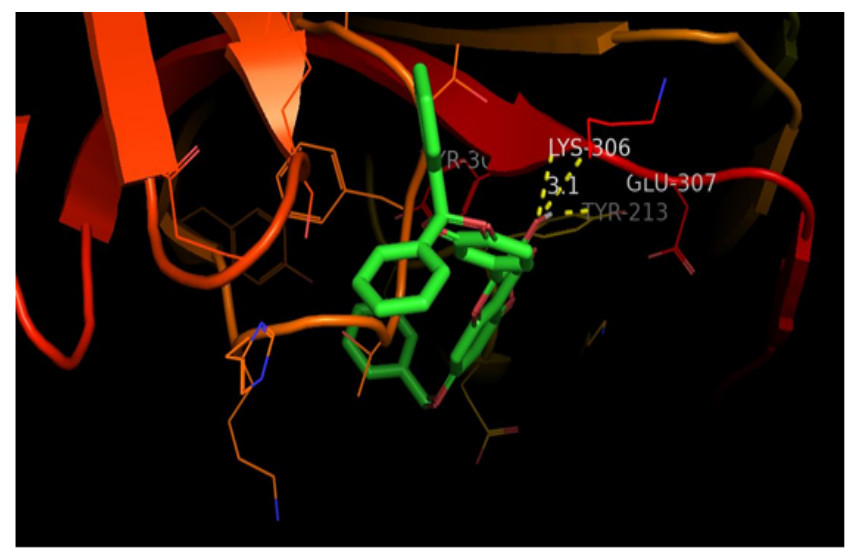

Protein-ligand(CID 716) interaction

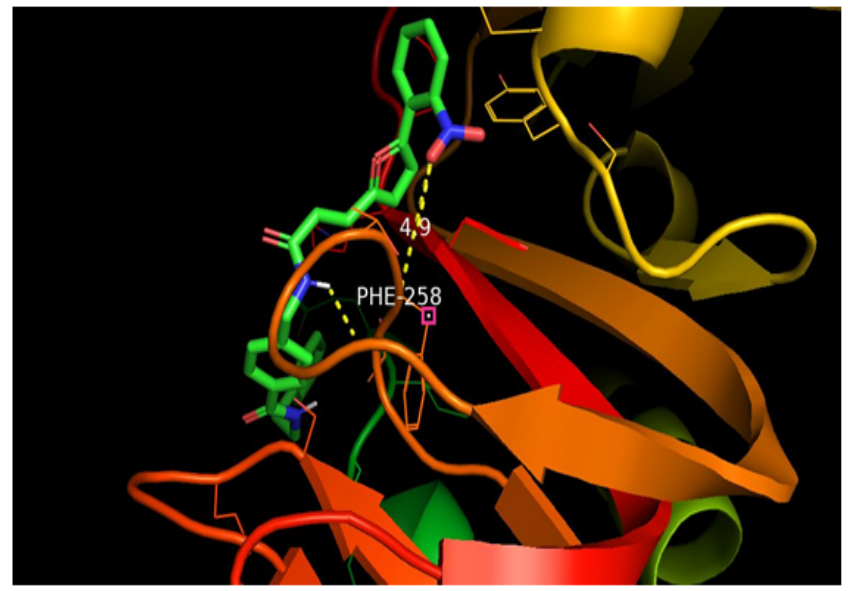

Protein-ligand(CID 475) interaction

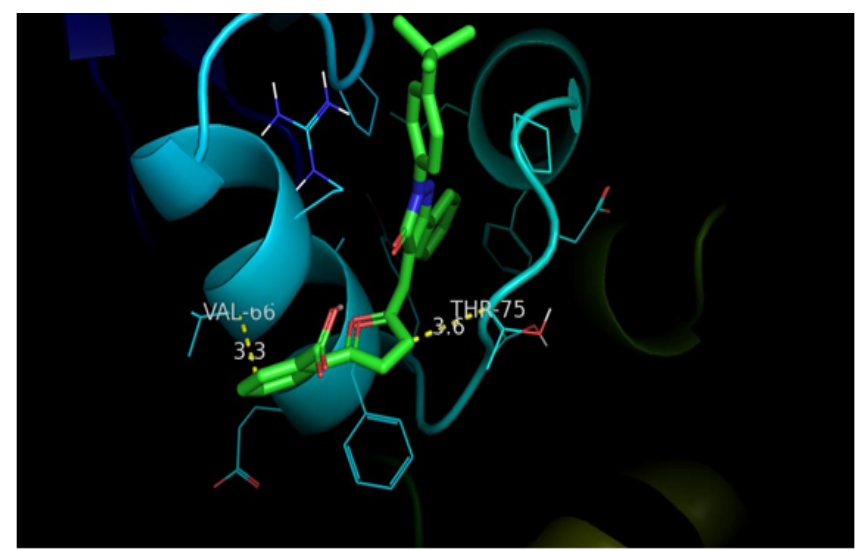

Protein-ligand(CID 221) interaction

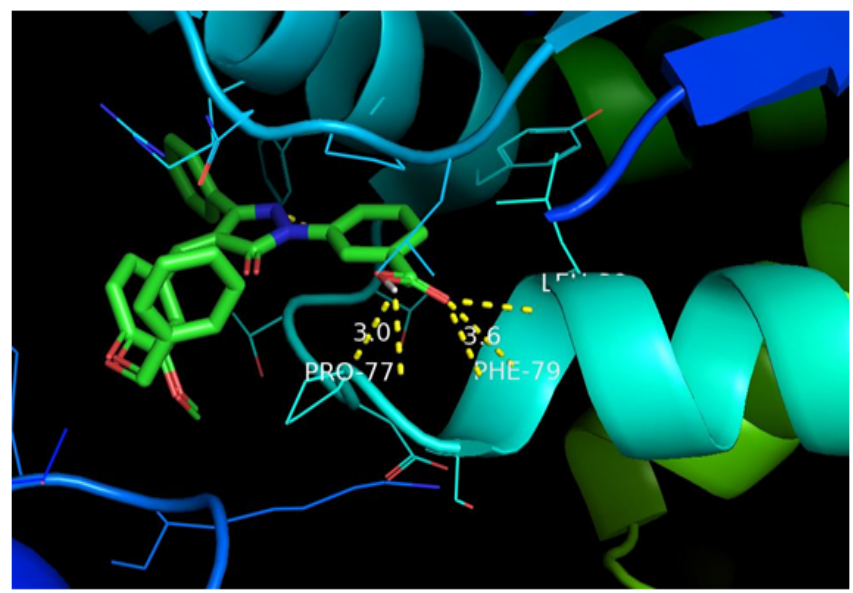

Protein-ligand(CID 403) interaction

Fig. 4a - Interaction of PLPro and drug lead compounds generated by the program 


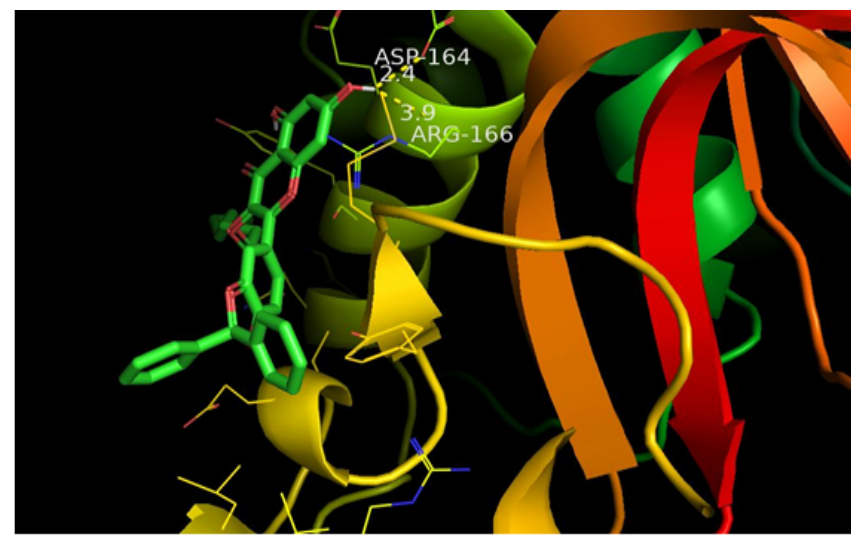

Protein-ligand(CID 054) interaction

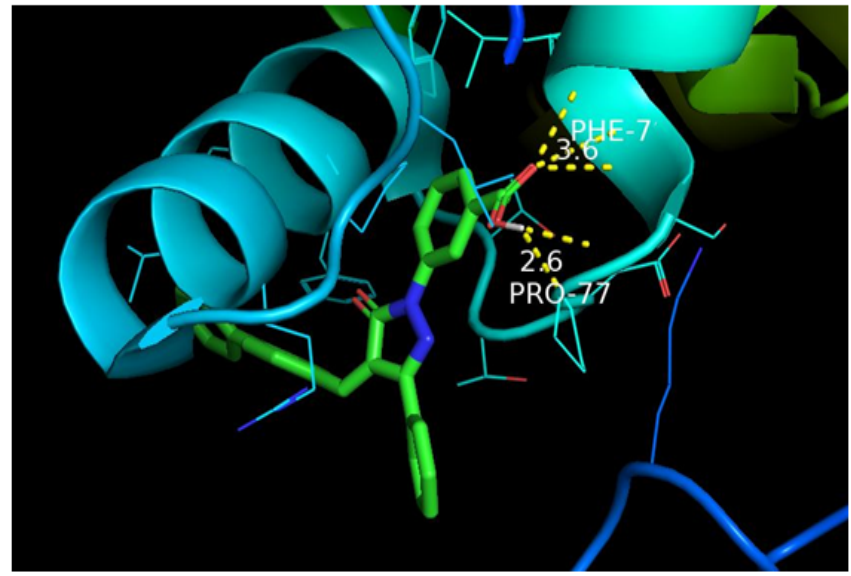

Protein-ligand(CID 229) interaction

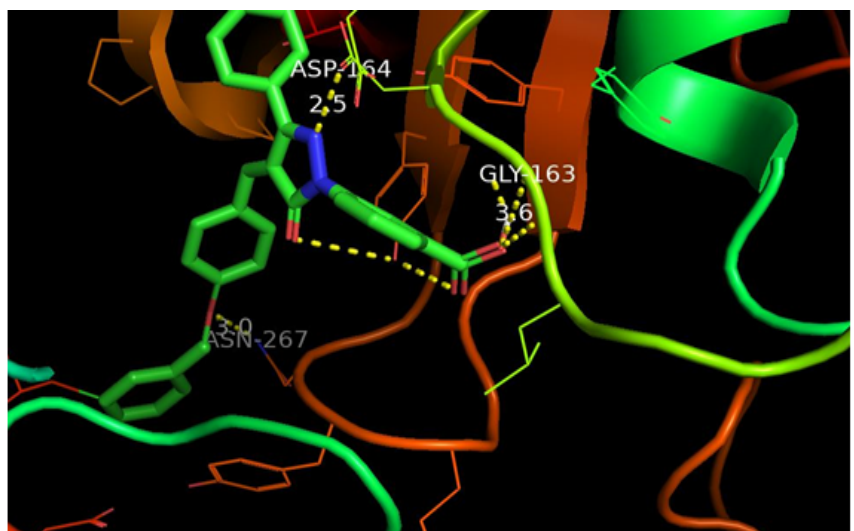

Protein-ligand(CID 386) interaction

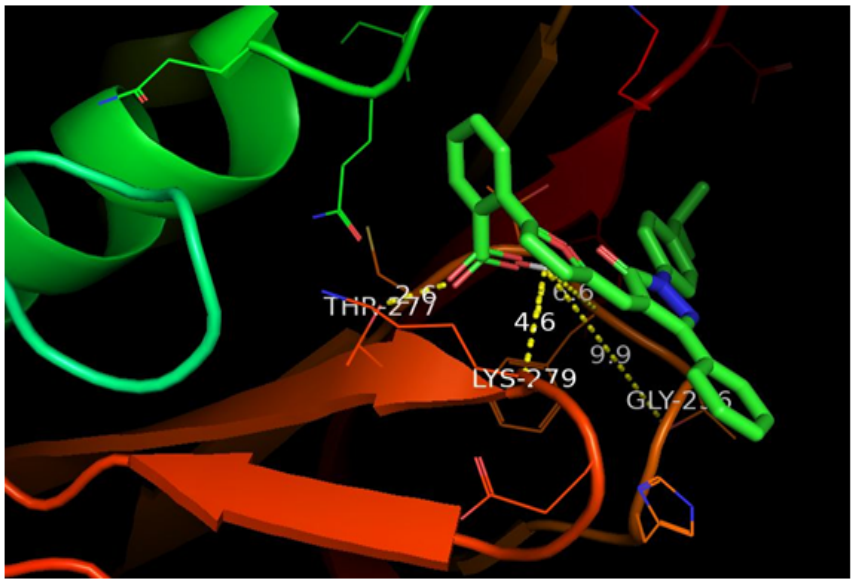

Protein-ligand(CID 220) interaction

Fig. 4b - Interaction of PLPro and drug lead compounds generated by the program

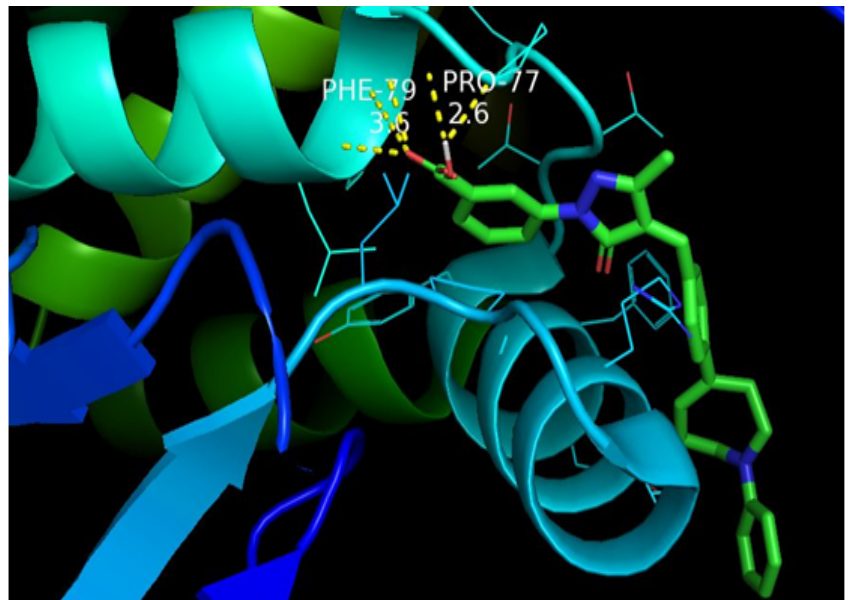

Protein-ligand(CID 197) interaction

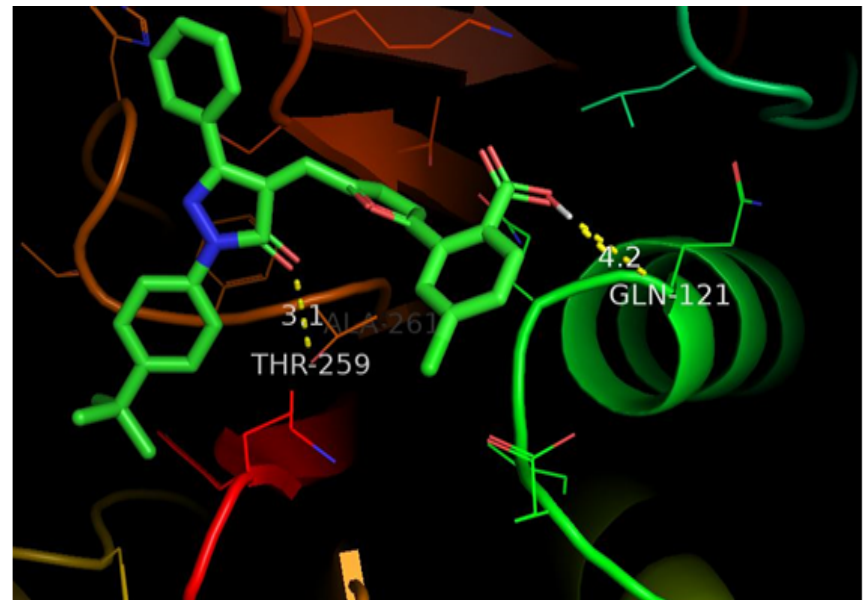

Protein-ligand(CID 642) interaction

Fig. 4c - Interaction of PLPro and drug lead compounds generated by the program 
Table 1 - PubChem CID and names of Compound generated as drug leads

\begin{tabular}{|c|c|c|}
\hline No. & PubChem CID & Compound Name \\
\hline 1 & CID 49856716 & $\begin{array}{l}\text { 2-(2,2-Diphenyl-1,3-benzodioxol-5-yl)-3,5-dihydroxy-7-phen } \\
\text { ylmethoxychromen-4-one }\end{array}$ \\
\hline 2 & CID 127045221 & $\begin{array}{l}\text { 2-[5-[(Z)-[1-(4-Tert-butylphenyl)-5-oxo-3-phenylpyrazol-4-yl } \\
\text { idene]methyl]furan-2-yl]benzoic acid }\end{array}$ \\
\hline 3 & CID 5470475 & $\begin{array}{l}\text { 4-[[[(E)-3-[5-(2-Nitrophenyl)furan-2-yl]prop-2-enoyl]amino] } \\
\text { methyl]-N-(2-phenylethyl)benzamide }\end{array}$ \\
\hline 4 & CID 4582403 & $\begin{array}{l}\text { 3-[4-[(3-Methoxy-4-phenylmethoxyphenyl)methylidene]-5-ox } \\
\text { o-3-phenylpyrazol-1-yl]benzoic acid }\end{array}$ \\
\hline 5 & CID 91808054 & $\begin{array}{l}\text { 3-(6-Chlorohexoxy)-2-(2,2-diphenyl-1,3-benzodioxol-5-yl)-5, } \\
\text { 7-dihydroxychromen-4-one }\end{array}$ \\
\hline 6 & CID 127045386 & $\begin{array}{l}\text { 3-[(4Z)-5-Oxo-3-phenyl-4-[(4-phenylmethoxyphenyl)methyli } \\
\text { dene]pyrazol-1-yl]benzoic acid }\end{array}$ \\
\hline 7 & CID 127045229 & $\begin{array}{l}\text { 3-[(4Z)-5-Oxo-3-phenyl-4-[(4-phenylphenyl)methylidene]pyr } \\
\text { azol-1-yl]benzoic acid }\end{array}$ \\
\hline 8 & CID 127045220 & $\begin{array}{l}\text { 2-[5-[(Z)-[5-Oxo-3-phenyl-1-(4-propan-2-ylphenyl)pyrazol-4- } \\
\text { ylidene]methyl]furan-2-yl]benzoic acid }\end{array}$ \\
\hline 9 & CID 143349197 & $\begin{array}{l}\text { 3-[(4Z)-3-Methyl-5-oxo-4-[[4-(1-phenyl-2,3,6,7-tetrahydroaz } \\
\text { epin-4-yl)phenyl]methylidene]pyrazol-1-yl]benzoic acid }\end{array}$ \\
\hline 10 & CID 127043642 & $\begin{array}{l}\text { 2-[5-[(Z)-[1-(4-Tert-butylphenyl)-5-oxo-3-phenylpyrazol-4-yl } \\
\text { idene]methyl]furan-2-yl]-4-chlorobenzoic acid }\end{array}$ \\
\hline 11 & CID 16429503 & $\begin{array}{l}\text { (4Z)-5-(4-Ethoxy-3-methoxyphenyl)-4-[hydroxy-(2-methyl-4- } \\
\text { phenylmethoxyphenyl)methylidene]-1-(3-methoxypropyl)pyrr } \\
\text { olidine-2,3-dione }\end{array}$ \\
\hline
\end{tabular}




\begin{tabular}{|c|c|c|}
\hline 12 & CID 127043642 & $\begin{array}{l}\text { 2-[5-[(Z)-[1-(4-Tert-butylphenyl)-5-oxo-3-phenylpyrazol-4-yl } \\
\text { idene]methyl]furan-2-yl]-4-chlorobenzoic acid }\end{array}$ \\
\hline 13 & CID 118970541 & $\begin{array}{l}\text { 2-(2,2-Diphenyl-1,3-benzodioxol-5-yl)-5,7-dihydroxy-3-prop } \\
\text { oxychromen-4-one }\end{array}$ \\
\hline 14 & CID 145041822 & $\begin{array}{l}\text { 2-(2-Cyclohexa-1,5-dien-1-yl-2-phenyl-1,3-benzodioxol-5-yl) } \\
\text {-5,7-dihydroxy-3-propoxychromen-4-one }\end{array}$ \\
\hline 15 & CID 5736973 & $\begin{array}{l}\text { Methyl } \\
\text { 2-[5-[(Z)-(5-oxo-1,3-diphenylpyrazol-4-ylidene)methyl]furan- } \\
\text { 2-yl]benzoate }\end{array}$ \\
\hline 16 & CID 127045222 & $\begin{array}{l}\text { 2-[5-[(Z)-[1-(4-Cyanophenyl)-5-oxo-3-phenylpyrazol-4-ylide } \\
\text { ne]methyl]furan-2-yl]benzoic acid }\end{array}$ \\
\hline 17 & CID 16429510 & $\begin{array}{l}\text { (4Z)-5-(3-Ethoxy-4-hydroxyphenyl)-4-[hydroxy-(2-methyl-4- } \\
\text { phenylmethoxyphenyl)methylidene]-1-(2-methoxyethyl)pyrro } \\
\text { lidine-2,3-dione }\end{array}$ \\
\hline 18 & CID 16429359 & $\begin{array}{l}\text { (4Z)-4-[(3,4-Dimethoxyphenyl)-hydroxymethylidene]-1-(3-m } \\
\text { ethoxypropyl)-5-(4-phenylmethoxyphenyl)pyrrolidine-2,3-dio } \\
\text { ne }\end{array}$ \\
\hline 19 & CID 16429509 & $\begin{array}{l}\text { (4Z)-5-(3,4-Dimethoxyphenyl)-4-[hydroxy-(2-methyl-4-phen } \\
\text { ylmethoxyphenyl)methylidene]-1-(2-methoxyethyl)pyrrolidin } \\
\text { e-2,3-dione }\end{array}$ \\
\hline 20 & CID 118970588 & $\begin{array}{l}\text { 2-(2,2-Diphenyl-1,3-benzodioxol-5-yl)-3-ethoxy-5,7-dihydrox } \\
\text { ychromen-4-one }\end{array}$ \\
\hline 21 & CID 127043643 & $\begin{array}{l}\text { (4Z)-2,5-Diphenyl-4-[(5-phenylfuran-2-yl)methylidene]pyraz } \\
\text { ol-3-one }\end{array}$ \\
\hline
\end{tabular}




\begin{tabular}{|c|c|c|}
\hline 22 & CID 16427940 & \\
\hline 23 & CID 16410715 & $\begin{array}{l}\text { 4-Methyl-N-[(Z)-3-(3-morpholin-4-ylpropylamino)-1-[5-(3-ni } \\
\text { trophenyl)furan-2-yl]-3-oxoprop-1-en-2-yl]benzamide }\end{array}$ \\
\hline 24 & CID 127045227 & $\begin{array}{l}\text { 2-[5-[(Z)-[1-(4-Methoxyphenyl)-5-oxo-3-phenylpyrazol-4-yli } \\
\text { dene]methyl]furan-2-yl]benzoic acid }\end{array}$ \\
\hline 25 & CID 145041849 & $\begin{array}{l}\text { 2-(2-Cyclohexa-1,5-dien-1-yl-2-phenyl-1,3-benzodioxol-5-yl) } \\
\text {-3-ethoxy-5,7-dihydroxychromen-4-one }\end{array}$ \\
\hline 26 & CID 52943505 & $\begin{array}{l}\text { 4-[(Z)-[1-(4-Tert-butylphenyl)-5-oxo-3-phenylpyrazol-4-ylide } \\
\text { ne]methyl]benzoic acid }\end{array}$ \\
\hline 27 & CID 127043644 & $\begin{array}{l}\text { 3-[(4Z)-5-Oxo-3-phenyl-4-[(5-phenylfuran-2-yl)methylidene }] \\
\text { pyrazol-1-yl]benzoic acid }\end{array}$ \\
\hline 28 & CID 127043645 & $\begin{array}{l}\text { 2-[5-[(Z)-(5-Oxo-1,3-diphenylpyrazol-4-ylidene)methyl]furan } \\
\text {-2-yl]benzoic acid }\end{array}$ \\
\hline 29 & CID 121513876 & $\begin{array}{l}\text { 4-[(4E)-3-Benzyl-4-[[5-(2-fluorophenyl)furan-2-yl]methylide } \\
\text { ne]-5-oxopyrazol-1-yl]benzoic acid }\end{array}$ \\
\hline 30 & CID 143349191 & $\begin{array}{l}\text { 3-[(4Z)-3-Benzyl-4-[[5-(2-fluorophenyl)furan-2-yl]methylide } \\
\text { ne]-5-oxopyrazol-1-yl]benzoic acid }\end{array}$ \\
\hline
\end{tabular}


Table 2 - Molecular Docking study of 3C1Pro and lead compounds

\begin{tabular}{|c|c|c|c|c|}
\hline Protein target & $\begin{array}{l}\text { PubChem ID of } \\
\text { compound }\end{array}$ & Bonded Reside & $\begin{array}{l}\text { Bond Length } \\
\left(\mathrm{A}^{0}\right)\end{array}$ & $\begin{array}{l}\text { Binding Energy } \\
(\mathrm{Kcal} / \mathrm{mol})\end{array}$ \\
\hline $\begin{array}{l}3 \text { Cysteine -like } \\
\text { Protease (PDB } \\
\text { ID 1P9U) }\end{array}$ & $\begin{array}{l}49856716 \\
127045221 \\
5470475 \\
4582403 \\
91808054 \\
127045386 \\
127045229 \\
127045220 \\
143349197 \\
127043642\end{array}$ & $\begin{array}{l}\text { GLY (167) } \\
\text { GLN (191) } \\
\text { TYR (280) } \\
\text { ARG (4) } \\
\text { LEU (164) } \\
\text { GLU (165) } \\
\text { ARG (4) } \\
\text { MLT (190) } \\
\text { GLN (191) } \\
\text { GLU (165) } \\
\text { GLN (191) } \\
\text { GLN (191) } \\
\text { GLY (167) } \\
\text { ASN (112) } \\
\text { GLN (8) } \\
\text { LYS (5) }\end{array}$ & $\begin{array}{l}4.4 \\
2.1 \\
2.6 \\
2.1 \\
3.0 \\
2.8 \\
2.2 \\
3.5 \\
2.6 \\
1.9 \\
5.1 \\
2.1 \\
4.4 \\
2.1 \\
2.7 \\
2.9\end{array}$ & $\begin{array}{l}-12.54 \\
-10.51 \\
-7.92 \\
-10.37 \\
-6.47 \\
-13.36 \\
-10.61 \\
-11.62 \\
-11.40 \\
-10.37\end{array}$ \\
\hline
\end{tabular}


Table 3 - Molecular Docking study of interaction of PLpro and lead compounds

\begin{tabular}{|c|c|c|c|c|}
\hline Protein target & $\begin{array}{l}\text { PubChem CID } \\
\text { of compound }\end{array}$ & Bonded Reside & $\begin{array}{l}\text { Bond Length } \\
\left(\mathrm{A}^{0}\right)\end{array}$ & $\begin{array}{l}\text { Binding } \\
\text { Energy } \\
(\mathrm{Kcal} / \mathrm{mol})\end{array}$ \\
\hline $\begin{array}{l}\text { Papain-like } \\
\text { Protease (PDB } \\
\text { ID 6X9C) }\end{array}$ & $\begin{array}{l}49856716 \\
127045221 \\
5470475 \\
4582403 \\
91808054 \\
127045386 \\
127045229 \\
127043642\end{array}$ & $\begin{array}{l}\text { LYS (306) } \\
\text { VAL (66) } \\
\text { THR (75) } \\
\text { PHE (258) } \\
\text { PRO (77) } \\
\text { PHE (79) } \\
\text { ASP (164) } \\
\text { ARG (166) } \\
\text { GYL (163) } \\
\text { ASP (164) } \\
\text { PRO (77) } \\
\text { PHE (79) } \\
\text { THR (277) } \\
\text { PHS (279) } \\
\text { PHE (79) } \\
\text { GLN (121) }\end{array}$ & $\begin{array}{l}3.1 \\
3.3 \\
3.6 \\
4.9 \\
3.0 \\
3.6 \\
2.4 \\
3.9 \\
3.6 \\
2.5 \\
2.6 \\
3.6 \\
2.6 \\
4.6 \\
3.6 \\
2.6 \\
3.1 \\
\end{array}$ & $\begin{array}{l}-11.36 \\
-10.90 \\
-9.35 \\
-10.54 \\
-7.44 \\
-10.58 \\
-9.71 \\
-9.03\end{array}$ \\
\hline
\end{tabular}

